\title{
Oral Administration of Dimethylarsinic Acid, a Main Metabolite of Inorganic Arsenic, in Mice Promotes Skin Tumorigenesis Initiated by Dimethylbenz(a)anthracene with or without Ultraviolet $B$
} as a Promoter

\author{
Kenzo Yamanaka, ${ }^{*, a}$ Mutsumi Mizor,${ }^{a}$ Koichi Kato, ${ }^{a}$ Akira Hasegana, ${ }^{a}$ Masayuki Nakano, ${ }^{b}$ and \\ Shoji OKADA ${ }^{c}$ \\ College of Pharmacy, Nihon University, ${ }^{a}$ 7-7-1 Narashinodai, Funabashi, Chiba 274-8555, Japan, National Mito \\ Hospital, ${ }^{b}$ 3-2-1 Higashi-hara, Mito 310-0035, Japan, and School of Pharmaceutical Sciences, University of Shizuoka, ${ }^{c}$ \\ 52-1 Yada, Shizuoka 422-8526, Japan. Received November 6, 2000; accepted January 19, 2001
}

\begin{abstract}
Concerning arsenic-induced tumorigenesis, an animal model must be developed for understanding the mechanism of human carcinogenesis by arsenics. To determine whether orally administered dimethylarsinic acid (DMA) promotes and causes the progression of skin tumorigenesis, an animal protocol by topical application of dimethylbenz(a)anthracene (DMBA) with or without UVB, a tumor promoter, in hairless mice was used. The administration of DMA by the oral route promoted not only the formation of papillomas induced by DMBA alone but also the formation of malignant tumors induced by way of the formation of atypical keratoses by treatment with DMBA and UVB. A phenomenon, the progression of keratoses $\rightarrow$ atypical keratoses $\rightarrow$ squamous cell carcinomas (SCCs), observed in the present study may resemble the development of tumors in arsenic-exposed humans. We also discussed the involvement of a reactive oxygen species (ROS), e.g., the dimethylarsenic peroxy radical $\left[\left(\mathrm{CH}_{3}\right)_{2} \mathrm{AsOO} \cdot\right]$, produced during the metabolic processing of DMA, in skin and in multi-organ tumorigenesis.
\end{abstract}

Key words dimethylarsinic acid; inorganic arsenic; dimethylbenz(a)anthracene; skin tumor; reactive oxygen species; tumor promotion

Inorganic arsenics have been linked epidemiologically to the induction of human skin and lung cancer by the International Agency for Research on Cancer (IARC); however, evidence in experimental animals with respect to their carcinogenicity has not yet been established. ${ }^{1)}$ DMA is a main metabolite of inorganic arsenics via methanearsonic acid (MMA) in mammals. ${ }^{2}$ This methylation pathway has historically been considered to be a detoxification process for the acute toxicity of inorganic arsenics. ${ }^{3)}$ However, our previous studies have demonstrated that the oral administration of DMA to mice induces lung-specific DNA damage ${ }^{4}$ and also exhibits promotion and progression effects on lung- and skintumorigenesis. ${ }^{5-7)}$ Multi-organ tumorigenesis due to the oral administration of DMA to rats has been also reported; DMA administration enhanced the incidence of tumors in liver, kidney, thyroid and urinary bladder induced by certain tumor initiators. ${ }^{8-10)}$ Moreover, in a study reported to the US Environmental Protection Agency (EPA), in which male and female rats and mice were fed DMA for 2 years, a carcinogenic response was found as evidenced by increases in urinary bladder tumors and fibrosarcomas. ${ }^{11)}$ On the other hand, some reports estimated that in vivo ${ }^{12,13)}$ and in vitro ${ }^{14)}$ exposure of arsenics produced a reactive oxygen species (ROS). Among the ROS, we have estimated the production of dimethylarsenic peroxy radicals in the metabolic processing of DMA ${ }^{15)}$ and that further, the radicals would be responsible for DNA damage and the promotion of lung- and skin-tumorigenesis in mice. ${ }^{4-7)}$ Collectively, these tumorigenic studies suggest that not DMA itself, but rather its metabolite(s), may promote of multi-organ tumorigenesis in rodents. ${ }^{16)}$

With regard to skin tumorigenesis by dimethylarsenics, recent reports ${ }^{17,18)}$ showed that by using K6/ODC transgenic mice that were overexpressed ornithine decarboxylase (ODC) in hair follicle keratinocytes, the application of DMA with or without dimethylbenz(a)anthracene (DMBA) enhanced the formation of papillomas in mice skin in a dose-dependent manner. However, these animal experiments would be limited due to the disadvantage of predominantly forming papillomas because squamous cell carcinoma (SCC) induced by arsenics occurs quite frequently after the formation of keratoses. ${ }^{19)}$ Thus, it is necessary to develop experimental models of skin tumorigenesis with the formation of keratoses, similar to the human skin carcinogenesis by arsenics. On the other hand, Wang et $a l^{20,21)}$ reported an animal model in which keratoacanthomas and SCCs are formed by irradiation with UVB, a skin-tumor promoter, in 7,12-dimethylbenz(a)anthracene (DMBA)-treated mice.

In the present study, we revealed that the oral administration of DMA has promotion and progression action in a skintumorigenesis model ${ }^{20,21)}$ of keratoacanthomas formation due to treatment with DMBA as an initiator and UVB as a promoter. We found that the administration of DMA by an oral route promoted not only the formation of papillomas by treatment with DMBA alone but also the formation of SCCs by way of the formation of atypical keratoses by treatment with both DMBA and UVB. Furthermore, to further clarify whether the promoting action of dimethylarsenics is due to the formation of reactive oxygen species (ROS) such as dimethylarsenic peroxy radicals, we analyzed 8-OHdG, a marker of oxidative stress, in urine after the administration of DMA to mice.

\section{MATERIALS AND METHODS}

Experimental Animals Six-week-old female Hos: HR-1 hairless mice and male ddY-strain mice were obtained from Sankyo Laboservice Corporation, Inc. (Tokyo, Japan). Mice, 
housed five per cage under specific pathogen-free (SPF) conditions with a $12 \mathrm{~h}$-light/dark cycle at $23 \pm 1{ }^{\circ} \mathrm{C}$ and $55 \%$ relative humidity, were given sterilized water and $\gamma$-ray-sterilized chow pellets from Funabashi Farm Co. (Funabashi, Japan) ad libitum.

Chemicals and UVB Light DMA was purchased from Nakalai Tesque (Kyoto, Japan), and recrystallized twice from methanol before use. DMBA was obtained from Wako Pure Chemical Industries, Ltd. (Osaka, Japan). The mice were treated with UVB as follows: each cage $(20 \times 15 \times 5 \mathrm{~cm})$ containing 5 mice was placed under an overhead UVB lamp (HP-15M, 280-380 nm, $\max$. $312 \mathrm{~nm}$; Atto Co., Tokyo, Japan) at an irradiation distance of $c a .10 \mathrm{~cm}$. The exposure time for a $0.3 \mathrm{~kJ} / \mathrm{m}^{2}$ dose of UVB was $33 \mathrm{~s}$. No detectable heat was produced during the irradiation. The UVB doses were determined at $302 \mathrm{~nm}$ with a radiometer (UVX31: UVP, Inc., CA, USA).

Skin Tumorigenesis in DMBA-Initiated Hairless Mice The hairless mice were tumor-initiated by a single topical application of $200 \mathrm{nmol}$ of DMBA dissolved in acetone $(100 \mu \mathrm{l})$. The mice thus treated were divided into 6 groups of 10 mice each and given tap water (control) or a solution of $400 \mathrm{ppm}$ or $1000 \mathrm{ppm}$ DMA ad libitum, and/or irradiated twice weekly with UVB at a dose of $0.3 \mathrm{~kJ} / \mathrm{m}^{2}$. The mice from each group were sacrificed at 50 weeks under nembutal anesthesia. The skin tumors which formed were counted, excised and fixed with buffered $10 \%$ formalin. Paraffin sections of the tumors were stained with hematoxylin and eosin.

Measurement of Urinary 8-OHdG The male ddYstrain mice were orally administered DMA at a dose of $720 \mathrm{mg} / \mathrm{kg}$ body weight. Urine was withdrawn with a syringe from the urinary bladder. The urine samples were placed in microtubes $(1.5 \mathrm{ml})$, centrifuged at $10000 \mathrm{rpm}$ for $15 \mathrm{~min}$, and the supernatant was used for the determination of 8OHdG using the competitive ELISA method with an "8OHdG Check" kit (Japan Institute for the Control of Aging, Shizuoka, Japan).

Statistics The differences in the percentage of mice with tumors between the groups administered DMA and the controls were analyzed by Fisher's exact test. Differences in the amount of 8-OHdG in urine samples between the mice administered DMA and the control mice $(0 \mathrm{~h})$ were calculated by analysis of variance (ANOVA) and Fisher's PLSD-test.

\section{RESULTS AND DISCUSSION}

Incidence of Skin Tumors Two experimental models of skin tumorigenesis were used in the present study to determine the ability of oral dimethylarsenics to promote skin-tumorigenesis and to further develop an animal model that makes it possible to understand the mechanism of human carcinogenesis by arsenics; the first is a model of skin tumorigenesis induced by DMBA alone, and the second with DMBA initiation and UVB used as a skin promoter. The latter animal model reported by Wang et $a l^{20,21)}$ is known to bring about the formation of keratoacanthomas and the subsequent formation of malignant carcinomas (SCCs).

Figure 1 shows the effect of DMA administration on the incidence of skin tumors induced by DMBA with (Fig. 1B) or without UVB $\left(0.3 \mathrm{~kJ} / \mathrm{m}^{2}\right)$ (Fig. 1A) in hairless mice. The oral administration of DMA to mice treated with DMBA

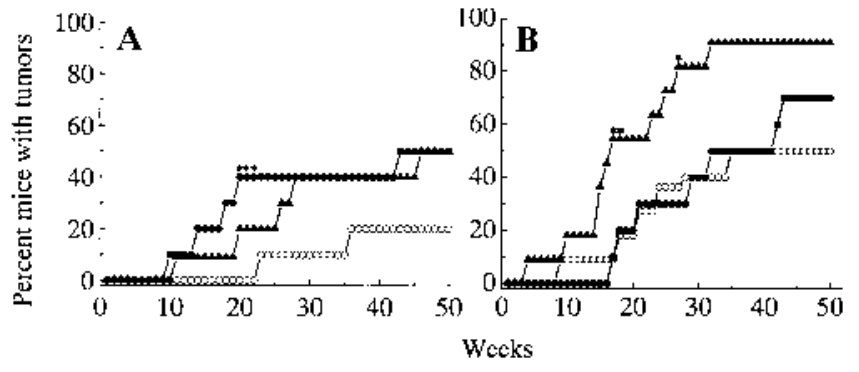

Fig. 1. Promoting the Effect of the Oral Administration of DMA on the Formation of DMBA-Initiated Skin Tumors in Hairless Mice

Female HR-1 mice were divided into 6 groups of 10 mice each. The mice were treated topically with $200 \mathrm{nmol}$ DMBA in $100 \mu \mathrm{l}$ of acetone. In groups shown in A and $\mathrm{B}$ at 1 week after DMBA treatment, the mice were given tap water $(O)$ or a DMA solution $(\boldsymbol{\Theta}, 400 \mathrm{ppm}, \boldsymbol{\Delta}, 1000 \mathrm{ppm})$ as the drinking fluid throughout the experimental period. In the groups shown in B, the mice were treated topically with DMBA, followed 1 week later by UVB treatment $\left(0.3 \mathrm{~kJ} / \mathrm{m}^{2}\right)$ twice weekly for 50 weeks. Tumors greater than $2-\mathrm{mm}$ in diameter were counted. * Significant difference $(p<0.05)$ from the group (control) given tap water. An asterisk (*) is marked at 20-22 weeks in A and at 16, 17 and 26 weeks in $\mathrm{B}$.

alone without UVB elicited an increase in the incidence of skin tumors (Fig. 1A). No dose-dependent relationship between the incidence of skin tumors and doses of DMA, however, was found.

As shown in Fig. 1B, when mice were exposed to both DMA, particularly at $1000 \mathrm{ppm}$, and UVB, the incidence of skin tumors was markedly higher than that by UVB alone (Fig. 1B, control). These results suggest that DMA is an oral route promoter for mouse-skin tumorigenesis and also that there is an appreciable interaction between dimethylarsenics and UVB in the promotion process.

Histopathological Examination Next, skin tumors which had been promoted by the oral administration of DMA and/or by irradiation with UVB at $0.3 \mathrm{~kJ} / \mathrm{m}^{2}$ were evaluated histopathologically (Table 1). When DMBA-treated mice were orally administered DMA, a more prominent formation of papillomas compared with the control (DMBA alone) was observed (Table 1A). The formation of SCC, however, was observed only in the control (DMBA alone).

When exposed to UVB, as shown in Table 1B, DMA administration caused not only a remarkable increase in papillomas but also, particularly at $1000 \mathrm{ppm}$ DMA, an increase in seborrheic keratosis with or without atypism and mitosis, compared with the control (UVB alone). SCC was also observed in the case of exposure to both DMA (particularly at $400 \mathrm{ppm}$ ) and UVB, but not in that of the control (UVB alone). The total number of pre-malignant tumors and SCCs was higher at higher doses of DMA (showed in Table 1B). These results suggest that in skin tumorigenesis induced by DMBA and UVB, the oral administration of DMA may not only promote the formation of papillomas and keratoses but also cause the progression of keratoses to malignant tumors.

Figures $2 \mathrm{~A}-\mathrm{C}$ present micrographs of tumors induced by exposure to both DMA (400 ppm) and UVB: Fig. 2A represents both seborrheic keratoses with mild atypism and SCC. Figures $2 \mathrm{~B}$ and $\mathrm{C}$, under higher magnification, show the portions of the tumor displayed in Fig. 2A. Figure 2B shows mild atypism with nuclear hyperchromasia and an irregular cell arrangement, and Fig. 2C shows SCCs. This diagnosis was never obtained in tumors shown in Table 1A, including SCCs. From the viewpoint of pathological diagnosis, the SCCs induced by way of the formation of pre-malignant 
Table 1. Histopathological Evaluations of Skin Lesions Initiated by DMBA

\begin{tabular}{|c|c|c|c|c|c|}
\hline Promoter & Papillomas & $\begin{array}{l}\text { Seborrheic } \\
\text { keratosis }\end{array}$ & $\begin{array}{l}\text { Seborrheic keratosis } \\
\text { with atypism and } \\
\text { mitosis (1) }\end{array}$ & $\begin{array}{l}\text { Squamous cell } \\
\text { carcinomas } \\
\text { (2) }\end{array}$ & $\begin{array}{l}\text { Premalignant and } \\
\text { malignat lesions } \\
(1)+(2)\end{array}$ \\
\hline \multicolumn{6}{|l|}{ (A) } \\
\hline None (control) & 1 & 1 & 0 & 2 & 2 \\
\hline 400 ppm DMA & 9 & 1 & 0 & 0 & 0 \\
\hline $\begin{array}{l}1000 \mathrm{ppm} \text { DMA } \\
\text { (B) }\end{array}$ & 7 & 2 & 0 & 0 & 0 \\
\hline $0.3 \mathrm{~kJ} / \mathrm{m}^{2} \mathrm{UVB}$ alone (control) & 0 & 6 & 3 & 0 & 3 \\
\hline $0.3 \mathrm{~kJ} / \mathrm{m}^{2} \mathrm{UVB}+400 \mathrm{ppm}$ DMA & 7 & 6 & 1 & 3 & 4 \\
\hline $0.3 \mathrm{~kJ} / \mathrm{m}^{2} \mathrm{UVB}+1000 \mathrm{ppm}$ DMA & 7 & 11 & 6 & 1 & 7 \\
\hline
\end{tabular}

All tumors greater than $2 \mathrm{~mm}$ in diameter were excised and then fixed with $10 \%$ buffered formalin. Histopathological evaluation of tumors induced by DMBA resulted in classification into four lesions as indicated above.
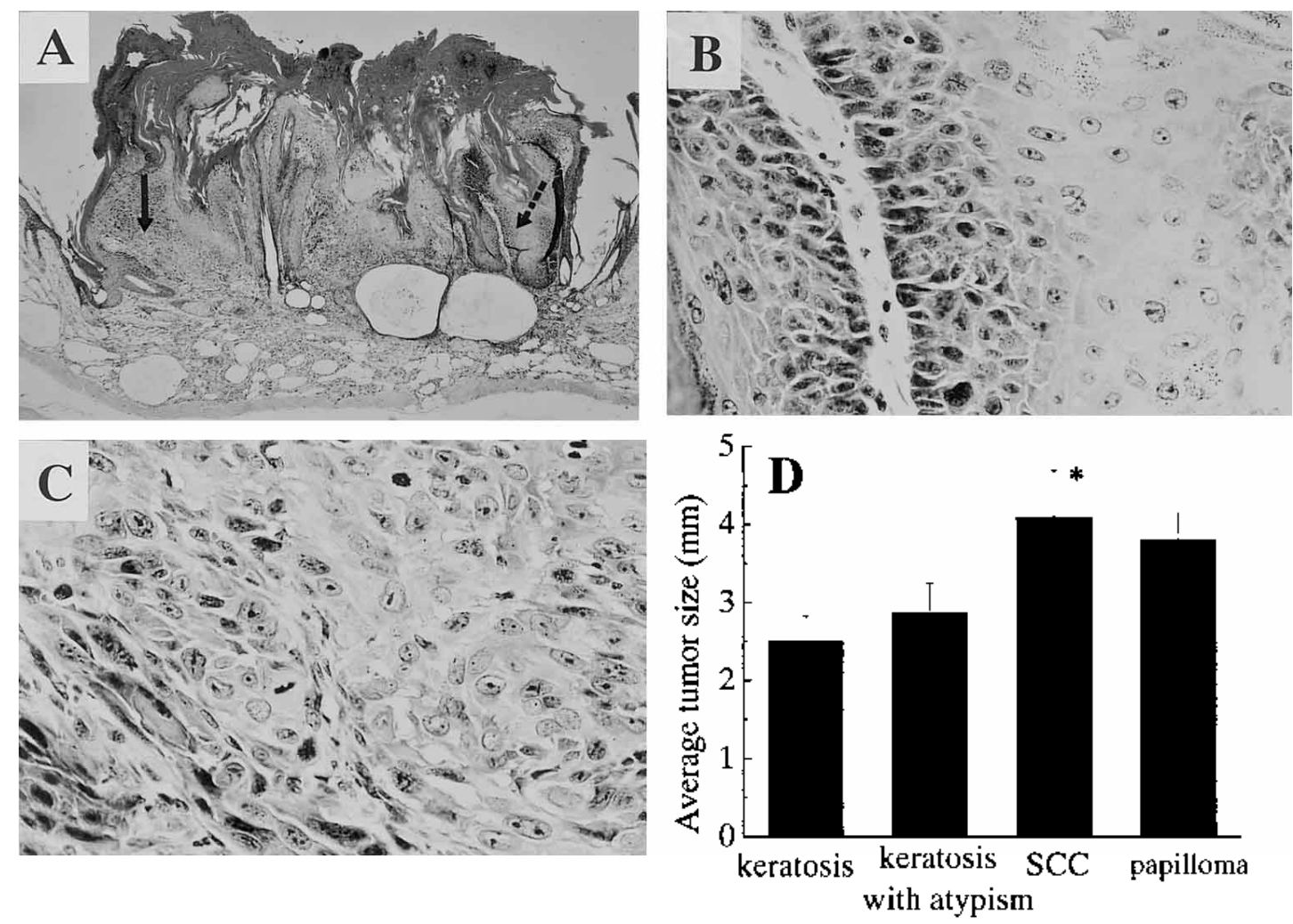

Fig. 2. Micrographs of a Tumor Induced by the Oral Administration of $400 \mathrm{ppm}$ DMA and Treatment with UVB (A-C) and the Average Size (Mean \pm S.E.) of the Tumors (D)

A: By histopathological evaluation $(\times 40)$, the tumor has two characteristics of atypism [mild atypism (broken arrow) and squamous cell carcinoma (solid arrow)]. The magnifications $(\times 400)$ of the sections indicated with broken and solid arrows in A, as mild atypism and squamous cell carcinomas, are shown in B and C, respectively. D: * Significant difference $(p<0.05)$ from the average sizes of keratosis.

lesions such as atypical keratosis (Table 1B) could be obviously distinct from those directly induced by DMBA alone (Table 1A). To ascertain whether this was the case, we measured the sizes of the tumors promoted by both DMA and UVB in DMBA-treated mice. As shown in Fig. 2D, tumor size was dependent on its degree of malignancy (keratosis $<$ keratosis with atypism $<$ carcinomas). The average size $(3.25 \mathrm{~mm})$ of two SCCs induced by the topical application of DMBA alone was smaller than those $(4.10 \pm 0.597 \mathrm{~mm})$ induced by treatment with DMA and UVB. These results suggest that the oral the administration of DMA also induces SCCs by the malignant progression of keratosis induced by DMBA and UVB. These results imply that dimethylarsenics have a diversity of effects in skin tu- morigenesis. Furthermore, there may be a resemblance between skin tumorigenesis induced by both DMBA and UVB and a part of the human carcinogenic process by arsenics. Since it seems that human SCCs created by exposure to arsenics may be caused by the progression of hyperkeratoses, ${ }^{19)}$ the animal model resulting in the progression of keratoses to SCCs would be useful for elucidating the mechanism of human skin carcinogenesis by arsenics.

Increase in 8-OHdG in Urine In an animal experimental model of multi-step carcinogenesis, ROS may have promotion and progression activity. ${ }^{22-24)}$ For example, benzoyl peroxide is known to promote and cause the progression of mouse skin tumorigenesis, ${ }^{25)}$ and its effects are considered to be due to ROS, e.g., benzoyloxyl radical and hydroxyl radi- 


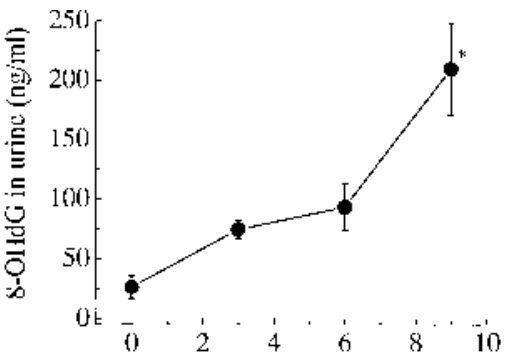

Timc alter administration of DWA (hr)

Fig. 3. The Amount of $8-\mathrm{OHdG}$ in Urine after the Oral Administration of DMA in ddY-Strain Mice

The mice were orally administered DMA $(720 \mathrm{mg} / \mathrm{kg})$. Each point represents the mean \pm S.E. $(n=5) *$ Significant difference $(p<0.001)$ from control $(0 \mathrm{~h})$

cal, which are produced during the metabolism of benzoyl peroxide. $^{26,27)}$

We have estimated that the promotion and progression of lung- and skin-tumorigenesis in mice is not directly ascribable to DMA itself, but to the dimethylarsenic peroxy radical $\left[\left(\mathrm{CH}_{3}\right)_{2} \mathrm{AsOO} \cdot\right]^{15)}$ produced during the metabolic processing of DMA. ${ }^{5-7)}$ This is a reactive oxygen species (ROS). There are two reports showing the positive data of 8-hydroxy-2'-deoxyguanosine $(8-\mathrm{OHdG})$, known as a product of oxidative damage due to ROS, by arsenic exposure: One demonstrated the enhancement of the amount of $8-\mathrm{OHdG}$ in the liver of rat by DMA exposure, ${ }^{12)}$ and another provided $8-\mathrm{OHdG}$ positive data in arsenic-related neoplasms and keratoses of humans. ${ }^{13}$ ) The latter suggested the relationship between arsenic and 8$\mathrm{OHdG}$ in an oxidative stress model of carcinogenesis in human skin tumors. However, analytical data of 8-OHdG in an experiment using mice has not yet been reported. On the other hand, some reports indicated that DMA exposure in rats increased the activity of ornithine decarboxylase (ODC), a tumor promotion marker, in the liver ${ }^{9,12)}$; conversely, DMA exposure in mice decreased that in the liver and lung, ${ }^{28)}$ although DMA administration promoted lung- and skin-tumorigenesis. ${ }^{5-9)}$ These facts suggest that rats are more responsive to dimethylarsenic than mice in terms of tumor promotion.

Based on these facts, it would be necessary to elucidate whether tumor-promoting action in mice by the oral administration of DMA may contribute to ROS produced from the metabolic processing of DMA. Therefore, we analyzed urinary $8-\mathrm{OHdG}$ excreted by repair excision from DNA in various tissues after acute exposure to DMA $(720 \mathrm{mg} / \mathrm{kg}$, p.o.) in ddY-strain mice which were utilized in a previous experiment ${ }^{5)}$ of lung-tumorigenesis by DMA exposure. As shown in Fig. 3, the amount of urinary 8-OHdG had a tendency to increase in a time-dependent manner after DMA administration, with a significant increase at $9 \mathrm{~h}$, suggesting that the formation of ROS such as dimethylarsenic peroxy radical could be responsible for the promotion and progression of skin tumorigenesis initiated by DMBA in mice.

The development of a putative animal model to clarify the mechanism(s) of multi-step carcinogenesis by arsenics is important. The promotion and progression activities of DMA found in the present study suggest important implications for the study of the mechanism(s) of multi-step carcinogenesis. We found that, in mice treated with DMBA, DMA and UVB, skin keratosis occurred, and then malignant skin tumors formed, similarly to cases reported for humans. ${ }^{19)}$ The oral administration of DMA enhances tumor formation in not only skin and lung ${ }^{5-7)}$ in mice, but also in the liver, kidney, urinary bladder and thyroid in rats. ${ }^{9)}$ It would be important to elucidate how ROS, such as the dimethylarsenic peroxy radical, are produced from DMA in biological systems, and how ROS exert their promoting and progressing activities. Furthermore, a mouse skin carcinogenesis model using DMA may be useful for studying the mechanism of arsenic skin carcinogenesis in humans.

Acknowledgement This work was supported by a Grant-in-Aid for Scientific Research (C) (No. 10672113) from the Ministry of Education, Science, Sports and Culture of Japan.

\section{REFERENCES}

1) IARC, "IARC Monographs on the Evaluation of Carcinogenic Risks to Humans; Overall Evaluations of Carcinogenicity: An Updating of IARC Monographs," Vol. 1 to 42, IARC, Lyon, 1987, pp. 100-106.

2) Vahter M. E., "Biological Monitoring of Toxic Metals," ed. by Clarkson T. W., Friberg L., Nordberg G. F., Sager P. R., Plenum Press, New York, 1988, pp. 303-321.

3) National Research Council (NRC), "Report: Arsenic in Drinking Water,” National Academy Press, Washington, D.C., 1999.

4) Okada S., Yamanaka K., "Induction of Lung-specific DNA Damage by Methylarsenics via the Production of Free Radicals, In: Nriagu J. O. (ed.), Arsenic in the Environment. Part II: Human Health and Ecosystem Effects," John Wiley \& Sons, New York, 1994, pp. 143-157.

5) Yamanaka K., Ohtsubo K., Hasegawa A., Hayashi H., Ohji H., Kanisawa M., Okada S., Carcinogenesis, 17, 767-770 (1996).

6) Hayashi H., Kanisawa M., Yamanaka K., Ito T., Udaka N., Ohji H., Okudela K., Okada S., Kitamura H., Cancer Lett., 125, 83-88 (1998).

7) Yamanaka K., Katsumata K., Ikuma K., Hasegawa A., Nakano M., Okada S., Cancer Lett., 152, 79-85 (2000).

8) Wanibuchi H., Yamamoto S., Chen H., Yoshida K., Endo G., Hori T., Fukushima S., Carcinogenesis, 17, 2435-2439 (1996).

9) Yamamoto S., Konishi Y., Matsuda T., Murai T., Shibata M., MatsuiYuasa I., Otani S., Kuroda K., Endo G., Fukushima S., Cancer Res., 55, 1271-1276 (1995).

10) Wei M., Wanibuchi H., Yamamoto S., Li W., Fukushima S., Carcinogenesis, 20, 1873-1876 (1996).

11) US EPA, Carcinogenicity Peer Review of Cacodylic Acid. Memorandum 400092, December, (1993).

12) Wanibuchi H., Hori T., Meenakshi V., Ichihara T., Yamamoto S., Yano Y., Otani S., Nakae D., Konishi Y., Fukushima S., Jpn. J. Cancer Res., 88, 1149-1154 (1997).

13) Mastui M., Nishigori C., Toyokuni S., Takada J., Akaboshi M., Ishikawa M., Imamura S., Miyachi Y., J. Invest. Dermatol., 113, 2631 (1999).

14) Ahmad S., Kitchin K. T., Cullen W. R., Arch. Biochem. Biophys., 382, 195-202 (2000).

15) Yamanaka K., Hoshino M., Okamoto M., Sawamura R., Hasegawa A., Okada S., Biochem. Biophys. Res. Commun., 168, 58-64 (1990).

16) Kitchin K. T., Toxicol. Appl. Pharmacol. (review article), in press (2001).

17) Chen Y., Megosh L. C., Gilmour S. K., Sawicki J. A., O’Brien T. G., Toxicol. Lett., 116, 27-35 (2000).

18) Morikawa T., Wanibuchi H., Morimura K., Ogawa M., Fukushima S., Jpn. J. Cancer Res., 91, 579-581 (2000).

19) Chen C.-J., Lin L.-J., "Human Carcinogenicity and Atherogenicity Induced by Chronic Exposure to Inorganic Arsenics, In: Nriagu J. O. (ed.), Arsenic in the Environment. Part II: Human Health and Ecosystem Effects," John Wiley \& Sons, New York, 1994, pp. 109-113.

20) Wang Z.-Y., Huang M.-T., Ferraro T., Wong C.-Q., Lou Y.-R., Reuhl K., Iatropoulos M., Yang C. S., Conney A. H., Cancer Res., 52, 1162-1170 (1992).

21) Wang Z. Y., Huang M.-T., Lou Y.-R., Xie J.-G., Reuhl K. R., Newmark 
H. L., Ho C.-T., Yang C. S., Conney A. H., Cancer Res., 54, 34283435 (1994).

22) Klaunig J. E., Xu Y., Isenberg J. S., Bachowski S., Kolaja K. L., Jiang J., Stevenson D. E., Walborg E. F., Jr., Environ. Health Perspect., 106, (Suppl. 1), 289-295 (1998).

23) Frenkel K., Chrzan K., Carcinogenesis, 8, 455-460 (1987).

24) Wei H., Frenkel K., Carcinogenesis, 14, 1195-1201 (1993).

25) Binder R. L., Aardema M. J., Thompson E. D., Prog. Clin. Biol. Res.,
391, 245-294 (1995).

26) Gimenez-Conti I. B., Binder R. L., Johnston D., Slaga T. J., Toxicol. Appl. Pharmacol., 149, 73-79 (1998).

27) Swauger J. E., Dolan P. M., Zweier J. L., Kuppusamy P., Kensler T. W., Chem. Res. Toxicol., 4, 223-228 (1991).

28) Ahmad S., Anderson W. L., Kitchin K. T., Cancer Lett., 139, 129135 (1999). 